\title{
POWERED VERSUS NON-POWERED ENDOSCOPIC DACRYOCYSTORHINOSTOMY IN THE TREATMENT OF NASOLACRIMAL DUCT OBSTRUCTION
}

\author{
By \\ Mohammed Ahmed El-Sharkawy and Ahmed Mahmoud Amin* \\ Departments of Otorhinolaryngology and Ophthalmology*, Faculty of Medicine, Al-Azhar \\ University (Cairo)

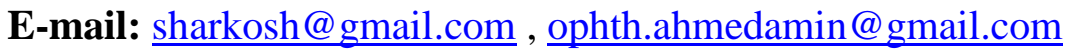

\begin{abstract}
Background: Nasolacrimal duct obstruction is a common cause of epiphora and purulent eye discharge which may need a surgical intervention in the form of dacryocystorhinostomy (DCR). External DCR was replaced by endoscopic DCR because of more precision, less trauma and less complications. A lot of techniques of endoscopic DCR were tried.

Objective: A comparison between non-powered technique (using a Kerrison's punch only) and powered technique (using a drill) as regard intra- and post-operative parameters.

Patients and methods: Forty patients with nasolacrimal duct obstruction were included in this study and divided into two equal groups: Group A who underwent powered DCR \& Group B who underwent nonpowered DCR at Al-Hussein University Hospital from July 2016 to August 2019. The data of certain intraand post-operative parameters were collected and statistically analyzed.

Results: Group A (powered) showed a statistically significantly higher mean time of bony work $(30.3 \pm 6.9)$ than Group B (non-powered) (17.2 \pm 3.4 ), Effect size was 2.408. There was no statistically significant difference between successes in the two groups. The success rate was higher in Group A (powered- $90 \%$ than Group B (non-powered - 85\%. There was no statistically significant difference between both groups as regard demographic data and minor complications.
\end{abstract}

Conclusion: Despite the nearly equal outcome of both techniques, non-powered DCR was safe, effective, affordable and took less time than powered technique.

Keywords: Epiphora, dacryocystorhinostomy, nasolacrimal, powered, non-powered.

\section{INTRODUCTION}

Dacryocystorhinostomy (DCR) is a procedure employed to relieve the symptoms of nasolacrimal drainage obstruction, such as distressing epiphora and purulent eye discharge. This procedure bypasses the site of obstruction by creating a direct channel of tear drainage from the lacrimal sac into the nasal cavity. However, it is effective only in cases of obstruction in the distal lacrimal apparatus (saccal and postsaccal) (Kumar et al., 2018).

DCR by the external approach, popularly known as external DCR, was first described by Toti in 1904. Endonasal DCR was first described in 1893 by Caldwell and was modified and popularized by West in 1910. McDonogh and Meiring were the first surgeon's 
utilized endoscopy in endonasal DCR in 1989. In the following period, many studies have reported modifications of endoscopic DCR to obtain higher success rates, fewer complications, and shorter operation and recovery times. Endoscopic DCR is commonly used because of its advantages, which include the prevention of an external scar, maintenance of the lacrimal pumping function, reduced operative time, shorter post-operative recovery time, less bleeding and the ability to simultaneously remove intranasal pathologies that may cause treatment failure (Dinc et al., 2018).

Furthermore, a lot of modifications of the endoscopic DCR technique has been introduced, which include nasal and lacrimal flap suturing, use of stents, use of mitomycin C (MMC), laser-assisted DCR, powered endoscopic DCR, radio frequency (RF)-assisted endoscopic DCR, balloon DCR, and a composite technique. Basically, endoscopic DCR essentially comprises the following: raising a mucoperiosteal flap, creating a bony window in the lacrimal fossa, removing the medial wall of the lacrimal sac completely, trimming the nasal mucoperiosteal flap, and placing it in close opposition with the remnant of medial wall of the sac without any gap or overlap. Other DCR techniques are modifications of some stage/s of standard endoscopic DCR aimed at improving success rates, reducing operating time, and minimizing complications (Sonkhya and Mishra 2009).

Kerrison's punch, hammer and chisel, and powered drill are one of the most commonly used instruments in DCR surgery.
In this study, a comparison was held between non-powered technique (using a Kerrison's punch only), and powered technique (using a drill) as regard intra-, and post-operative parameters.

\section{PATIENTS AND METHODS}

This study was a randomized controlled study with 1:1 allocation ratio. The study was conducted at Al-Hussein University Hospital from July 2016 to August 2019 on 40 patients.

\section{Inclusion criteria:}

- Patients ranging from 6-63 yrs.

- Patients with symptomatic unilateral acquired epiphora due to distal obstruction of the nasolacrimal duct, confirmed by lacrimal irrigation and radiological findings.

- Fitness of the cases for general anesthesia.

\section{Exclusion criteria:}

1. Nasal pathology like septal deviation, polyps or tumors.

2. Punctal ectropion.

3. Epiphora because of lower lid laxity.

4. Epiphora due to facial palsy.

5. Lithiasis.

6. Proximal obstruction.

7. Tumor of the lacrimal apparatus.

8. History of previous ocular or nasal surgery.

All patients underwent full history taking, ophthalmologic examination, endoscopic examination, lacrimal irrigation and CT of the nose and paranasal sinuses. 
Pre-operative investigations were done for $\mathrm{CBC}$, ESR, coagulation profile, PT, $\mathrm{PC}$, and INR.

The surgical procedures, benefits and harms of the surgical procedures were explained to the patients and written consents were obtained. Patients were randomly \& equally allocated into 2 groups.

All patients underwent endoscopic endonasal DCR. Starting by injecting the operating site then making a longitudinal incision over the maxillary line (overlying the frontal process of maxilla) extending superiorly from $10 \mathrm{~mm}$ above the axilla of the middle turbinate down to just above the inferior turbinate, then creating two horizontal incisions starting from both ends of longitudinal incision and extending posteriorly to create a posteriorly based flap. Then, the flap was dissected and everted posteriorly to expose the frontal process of maxilla to be prepared for the bony work.

Group A: The exposed bone of frontal process of maxilla and agger nasi was removed using powered drill with irrigation using a diamond burr at a low speed figure (1).

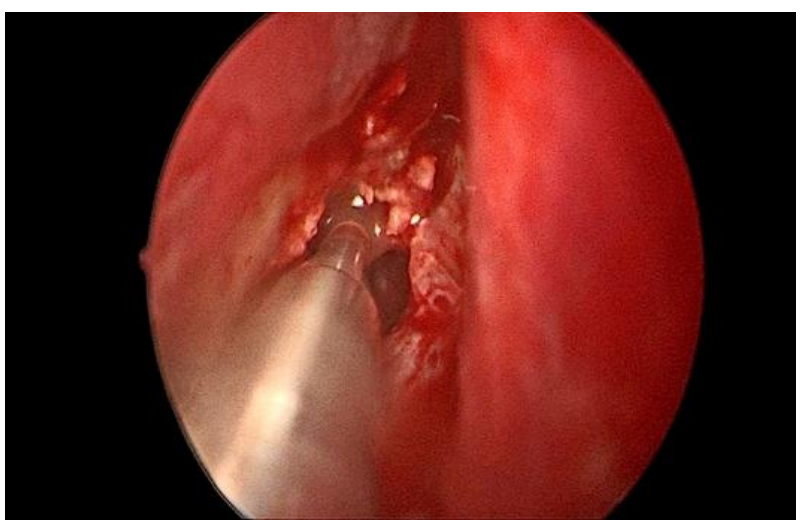

Figure (1): Drilling of frontal process of maxilla

Group B: The exposed bone of frontal process of maxilla and agger nasi was removed using only an upward Kerrison's punch $\left(90^{\circ} \& 45^{\circ}\right.$ angle) with different sizes. Some difficult cases required drills to complete the work done by Kerrison's punch were excluded from the study figure (2).

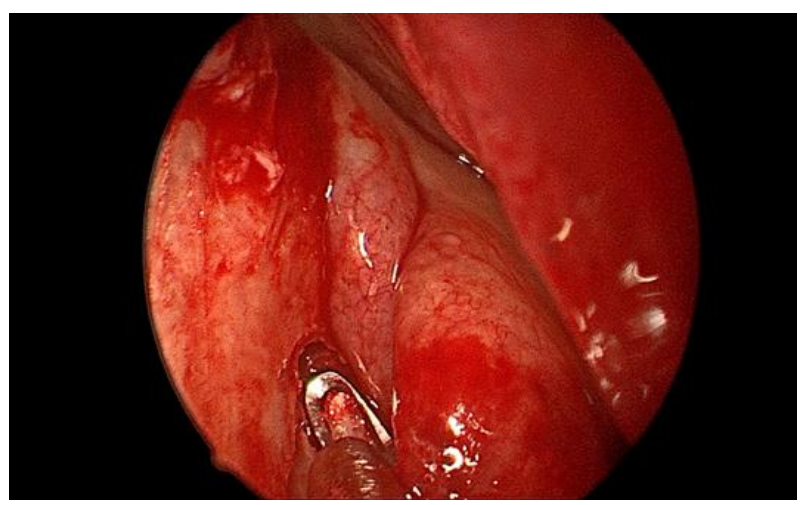

Figure (2): Biting of frontal process by Kerrisson's punch 


\section{After bone removal and exposure of the lacrimal sac, all patients have undergone the following:}

- Dilation of the lacrimal puncti.

- Probing through superior punctum and canaliculus Causing tenting of the medial wall of the sac.

- H-shaped incision was done to the medial wall of the sac while tented (to avoid injury of the sac mucosa).

- Insertion of the silicon tube

- The posterior flap of the sac was removed, while the anterior one was everted anteriorly.

- The nasal mucosal flap was divided into superior part covering the incised sac, and the inferior part covering the nasolacrimal, and the remaining frontal process of maxilla.

- The superior part was inverted inside the sac, while the inferior part was repositioned.

- The silicon tube was knotted outside the nose, and then left to recoil.

- No tampon was inserted.

All patients received post-operative intravenous antibiotic injections (sultamicillin) for 48 hrs., followed by oral antibiotics (amoxicillin + clavulanate) + anti- inflammatory oral drugs, and were instructed to perform nasal saline douching, and using antibiotic-steroid eye drops for one week. Nasal douching was continued until the rhinostomy was entirely healed.

The patient was followed up every week for the first month, then every month for the next 3 months. Every visit, the nose was endoscopically examined for patency of rhinostomy opening, position of silicon tube and all of granulation tissue and crustations were removed. At the end of the visits, the silicone tube was removed.

Both techniques were compared according to operative time (of bony work), functional success (which includes anatomical success [depending on a patent rhinostomy opening on endoscopic examination] \& relief of symptoms), failure due to synechia formation, intraoperative \& postoperative complications.

\section{Statistical analysis:}

Exploration of numerical data for normality was by checking the distribution of data and using tests of normality (Kolmogorov-Smirnov and Shapiro-Wilk tests). Age data showed non-normal (non-parametric) distribution while time of bony work data showed normal (parametric) distribution. Data presentation was as mean and standard deviation values. Student's t-test was used for parametric data to compare between the two groups. Mann-Whitney U test was used for non-parametric data to compare between the two groups. Qualitative data presentation was as frequencies and percentages. Chi-square and Fisher's exact tests were used to compare between the two groups. The significance level was at the value of $P \leq 0.05$. IBM SPSS Statistics for Windows, Version 23.0. Armonk, NY: IBM Corp. was used for statistical analysis. 


\section{RESULTS}

There was no statistically significant difference between mean age values in the two groups. There was also no statistically significant difference between gender distributions as well as affected eye distribution in the two groups (Table 1).

Table (1): Mean, standard deviation (SD), frequencies (n), percentages and results of Mann-Whitney U test and Chi-square test and Fisher's Exact test for comparisons of demographic data of the two groups

\begin{tabular}{|c|c|c|c|}
\hline Groups & $\begin{array}{c}\text { Group (A) } \\
\text { Powered (Drill) } \\
\text { (N=20) }\end{array}$ & $\begin{array}{c}\text { Group (B) } \\
\text { Non-powered (Kerrison) } \\
\text { (N=20) }\end{array}$ & $P$-value \\
\hline $\begin{array}{c}\text { Age (Years) } \\
\text { Mean (SD) }\end{array}$ & $34.1(13.4)$ & $32.1(14.1)$ & $>0.05$ \\
\hline $\begin{array}{c}\text { Gender [n (\%)] } \\
\text { Male }\end{array}$ & $\begin{array}{c}\text { 13(65) } \\
7(35)\end{array}$ & $10(50)$ & $>0.05$ \\
Female & $10(50)$ & $>0.05$ \\
\hline $\begin{array}{c}\text { Affected eye [n (\%)] } \\
\text { Right } \\
\text { Left }\end{array}$ & $\begin{array}{c}11(55) \\
\text { Bilateral }\end{array}$ & $\begin{array}{c}(45) \\
11(55)\end{array}$ & \\
\hline
\end{tabular}

Epiphora was the main presenting feature in the majority of cases (17 cases [85\%] in group A \& 16 in group B [80\%]), followed by purulent eye discharge (13 cases [65\%] in group A \& 14 in group B [70\%]), with no statistically significant difference between presenting features in the two groups (Table 2).

Table (2): Frequencies, percentages (\%), results of Fisher's Exact test and Chisquare test for comparison between presenting features in the two groups

\begin{tabular}{|c|c|c|c|}
\hline Groups & $\begin{array}{c}\text { Group (A) } \\
\text { Powered (Drill) } \\
\text { N=20 }\end{array}$ & $\begin{array}{c}\text { Group (B) } \\
\text { Non-powered (Kerrison) } \\
\text { N=20 }\end{array}$ & $P$-value \\
\hline $\begin{array}{c}\text { Presenting features } \\
\text { Epiphora }\end{array}$ & $17(85)$ & $16(80)$ & $>0.05$ \\
Purulent eye discharge & $13(65)$ & $14(70)$ & $>0.05$ \\
\hline
\end{tabular}

Group A (powered) showed a (non-powered) (17.2 \pm 3.4$) \quad$ (P-value statistically significantly higher mean time $\quad<0.001$, Effect size $=2.408)$. of bony work $(30.3 \pm 6.9)$ than Group B

Table (3): Mean, standard deviation (SD) values and results of Student's t-test for comparison between time of bony work (minutes) in the two groups

\begin{tabular}{|c|c|c|c|c|}
\hline Groups & $\begin{array}{c}\text { Group (A) } \\
\text { Powered (Drill) } \\
\mathrm{N}=20\end{array}$ & $\begin{array}{c}\text { Group (B) } \\
\text { Non-powered (Kerrison) } \\
\mathrm{N}=20\end{array}$ & $P$-value & Effect size \\
\hline $\begin{array}{c}\text { Time (Minutes) } \\
\text { Mean (SD) }\end{array}$ & $30.3(6.9)$ & $17.2(3.4)$ & $<0.001 *$ & 2.408 \\
\hline
\end{tabular}


There was no statistically significant difference between success in the two groups $(\mathrm{P}$-value $=1.000)$. But the success rate was higher in Group A (powered) $90 \%$ (18) than Group B (non-powered) $85 \%$ (17). There were no major complications in all cases like uncontrolled bleeding, orbital injury or CSF rhinorrhea.

Group A (powered) showed non statistically significant higher rate of granulation tissue formation $10 \%$ (2) than Group B (non-powered) 5\% (1) (P-value = 1.000). All cases with granulation were treated by debridement during follow up + intra-nasal corticosteroid. There was no statistically significant difference between presence of infection in the two groups ( $\mathrm{P}$ value $=0.605)$. But the presence of infection was higher in Group A (powered) $15 \%$ (3) than that in Group B (non-powered) 5\% (1). These cases were treated by systemic antibiotic e.g. Amoxycillin-clavulanate.

Group A (powered) showed non statistically significant higher rate of stent migration $20 \%$ (4) than that in Group B (non-powered) 10\% (2) (P-value $=0.661)$. This migration was tried to be corrected in out-patient clinic but two of them needed repositioning under general anesthesia (Table 4).

Table (4): Frequencies, percentages (\%) and results of Fisher's Exact test for comparison between post-operative parameters in the two groups

\begin{tabular}{|c|c|c|c|}
\hline Groups & $\begin{array}{c}\text { Group (A) } \\
\text { Powered (Drill) } \\
\text { N=20 }\end{array}$ & $\begin{array}{c}\text { Group (B) } \\
\text { Non-powered (Kerrison) } \\
\text { N=20 }\end{array}$ & $P$-value \\
\hline Outcome & $18(90)$ & $17(85)$ & $>0.05$ \\
Success & $2(10)$ & $3(15)$ & \\
Failure & $2(10)$ & $1(5)$ & $>0.05$ \\
Complications & $3(15)$ & $1(5)$ & $>0.05$ \\
Granulation & $4(20)$ & $2(10)$ & $>0.05$ \\
Infection & & & \\
Stent migration &
\end{tabular}

\section{DISCUSSION}

Nasolacrimal duct (NLD) obstruction is a common pathology that can be treated with various types of approaches, both surgical and non-surgical (Huang et al., 2014). Dacryocystorhinostomy (DCR) is considered as the optimum intervention for a symptomatizing nasolacrimal duct (NLD) obstruction which can be either external or endonasal (Spielmann et al., 2009). Endonasal endoscopic DCR has been well established because of not only less surgical trauma, low postoperative discomfort, and greater cosmetic accessibility, but also, as a highly successful procedure when compared with the transcutaneous incision approach $(\mathrm{Su}$, 2018).

The most common cause for the failure of surgery is the formation of granulation, cicatricial closure of the osteotomy site or common canalicular obstruction (Coumou et al., 2017).

There was no statistically significant difference between mean age values in the two groups which was similar to the findings of Çukurova et al. (2018).

There was also no statistically significant difference between gender distributions which came against to 
Trimarchi et al. (2019) who found that the male to female ratio was $1: 2.6$, and also, contrary to Cukurova et al. (2018) where there was a female predominance in both groups with no statistically significant difference.

For the affected eye distribution, the right eye was more dominant in group A (11) with no bilateral cases, opposite to the group B where the left eye was more dominant with only one bilateral case which comes against Çukurova et al. (2018) where there was a predominance of the left eye in both groups, and also, is contrary to Dinc et al. (2018) who found a predominance of the left eye in over all patients included in the study, with no statistically significant difference in both studies.

Also, Shin et al. (2018) found nonsignificant difference as regarding the demographic data between the studied groups.

Epiphora was the main presenting feature in presented cases, followed by purulent eye discharge, with no statistically significant difference between presenting features in the two groups. Kumar et al. (2018) found similar results where epiphora was the main presenting feature in the majority of cases. Followed by purulent eye discharge (76.35\%). Also, Herzallah et al. (2019) found that epiphora was the main presenting feature and found in all presented cases.

The time for removal of the bone covering the sac (bony work) was calculated because it was technically different and comparable; otherwise, all steps of the technique were the same. Group A (powered) showed statistically significantly higher mean time of bony work $(30.3 \pm 6.9)$ than Group B (nonpowered). These results agreed with that of Kumar et al. (2018). This little difference is due to use of Kerrison's punch first before using the drill in the powered group.

The functional success of surgery was assessed which does not only depend of anatomical success (the patency of rhinostomy opening on endoscopic examination) but also, depends on relief of pre-operative symptoms. There was no statistically significant difference between successes in the two groups. But the success rate was higher in Group A (powered) than Group B (non-powered) which agreed with the success rate of Kumar et al. (2018) which is higher in powered group than non-powered group with no statistically significant difference.

Kingdom et al. (2020) had a comparable success rate of powered DCR with that of the powered group of this study and also, comparable with that of Trimarchi et al. (2019).

The success rate of non-powered group $(85 \%)$ in this study was comparable with that in the study of Dinc et al. (2018) who underwent non-powered DCR, and with Herzallah et al. (2019), and with the mean success rate of over all cases in Shin et al. (2018).

There were no major complications in all cases like uncontrolled bleeding, orbital injury or CSF rhinorrhea. Group A (powered) showed non statistically significant higher rate of granulation tissue formation which came in agreement with Kumar et al. (2018) who found that the granulation tissue formation was higher in powered group than non- 
powered group with no significant difference.

There was no statistically significant difference between presences of infection in the two groups. But the presence of infection was higher in Group A (powered) than that in Group B (nonpowered).

Group A (powered) showed non statistically significant higher rate of stent migration than that in Group B (nonpowered) which agrees with Kumar et al. (2018) where the powered group had a higher rate of stent migration than nonpowered group with no statistically significant difference.

Trimarchi et al. (2019) had a comparable granulation tissue formation rate, and also, comparable stent migration rate in patients underwent powered DCR with that of the powered group of this study, and also, comparable with that of Kingdom et al. (2020).

Also, Dinc et al. (2018) had a comparable granulation tissue formation rate and infection rate in group 2 who underwent non-powered DCR with that of non-powered group in this study.

\section{CONCLUSION}

Both techniques of powered (using the drill) and non-powered (using Kerrison's punch) have a nearly comparable results of success rate and complications, but the non-powered technique has much less time of bone removal and still costs less.

\section{REFERENCES}

1. Coumou AD, Genders SW, Smid TM. and Saeed P. (2017): Endoscopic dacryocystorhinostomy: long-term experience and outcomes. Acta Ophthalmol., 95:74-78.

2. Çukurova I, Bulğurcu S, Arslan IB. and Dikilitaş BJ. (2018): Comparison of Piezosurgery and Hammer-Chisel in Endoscopic Dacryocystorhinostomy. Craniofac Surg., 29(6):1612-1613.

3. Dinc ME, Ulusoy $\mathbf{S}$, Sahin E, Bozan N, Avincsal MO, Tutar B. and Uyar Y. (2018): The use of an ostial stent does not increase the success rate of endoscopic dacryocystorhinostomy. J Laryngol Otol., 132(8):718-723.

4. Herzallah IR, Marglani OA, Alherabi AZ, Faraj NS. and Bukhari DH. (2019): Bilateral Simultaneous Endoscopic Dacryocystorhinostomy: Outcome and Impact on the Quality of Life of the Patients. Int Arch Otorhinolaryngol., 23(2):191-195.

5. Huang J, Malek J, Chin D, Snidvongs K, Wilcsek G, Tumuluri K, Sacks R. and Harvey RJ. (2014): Systematic review and meta-analysis on outcomes for endoscopic versus external dacryocystorhinostomy. Orbit, 33(2): 8190.

6. Kingdom TT, Barham HP. and Durairaj VD. (2020): Long-term outcomes after endoscopic dacryocystorhinostomy without mucosal flap preservation. Laryngoscope, 130(1):12-17.

7. Kumar S, Mishra AK, Sethi A, Mallick A, Maggon N, Sharma H. and Gupta A. (2018): Comparing Outcomes of the Standard Technique of Endoscopic DCR with Its Modifications: A Retrospective Analysis. Otolaryngology-Head and Neck surgery, 160(2):347-354.

8. Shin HY, Paik JS. and Yang SW. (2018): Clinical Results of Anti-adhesion Adjuvants after Endonasal 
Dacryocystorhinostomy. Korean J Ophthalmol., 32(6):433-437.

9. Sonkhya N. and Mishra P. (2009): Endoscopic transnasal dacryocystorhinostomy with nasal mucosal and posterior lacrimal sac flap. $\mathbf{J}$ Laryngol Otol., 123:320-326.

10. Spielmann PM, Hathorn I, Ahsan F, Cain AJ. and White PS. (2009): The impact of endonasal dacryocystorhinostomy (DCR), on patient health status as assessed by the Glasgow benefit inventory. Rhinology, 47(01):48-50.
11. Su PY. (2018): Comparison of endoscopic and external dacryocystorhinostomy for treatment of primary acquired nasolacrimal duct obstruction. Taiwan J Ophthalmol., 8:1923.

12. Trimarchi M, Giordano Resti A, Vinciguerra A, Danè G. and Bussi $M$. (2019): Dacryocystorhinostomy: Evolution of endoscopic techniques after 498 cases. Eur J Ophthalmol., 10:11-20. 
مقارنة بين الجر احة المنظارية للكيس الدمعي المدعومة بالطاقة و غير المدعومة في علاج انسداد القناة الدمعية الأنفية

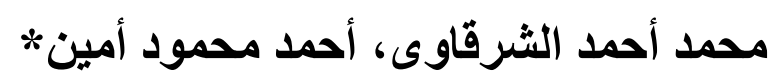

قسمي الأنف والأذن والحنجرة وطب و جراحة العيون*، كلية الطب، جامعة الأزهر

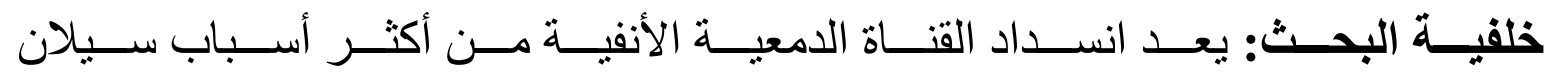

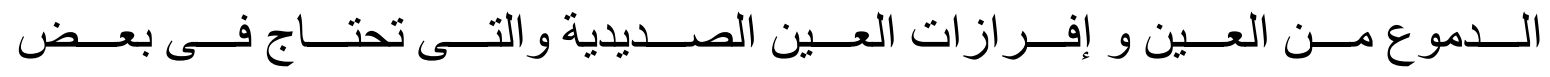

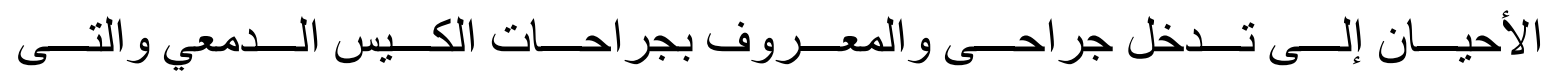

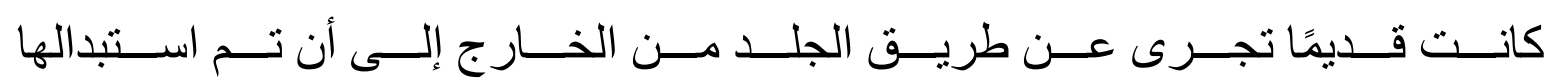

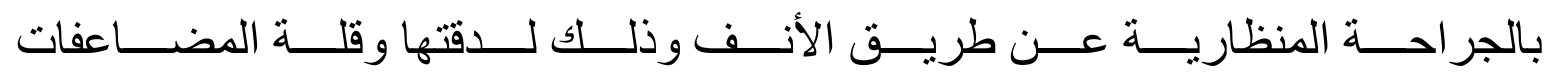

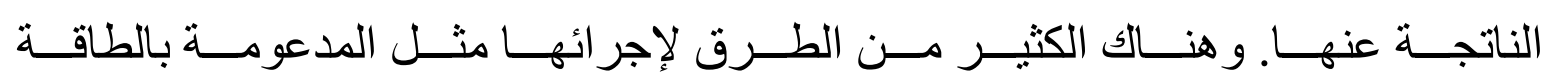
أو المدعومة بالليزر أو التى تتم بدون دعامات.

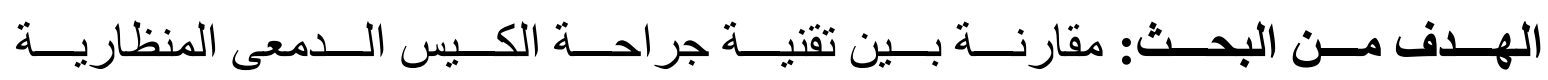

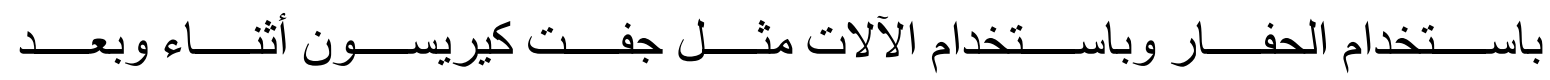

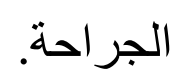

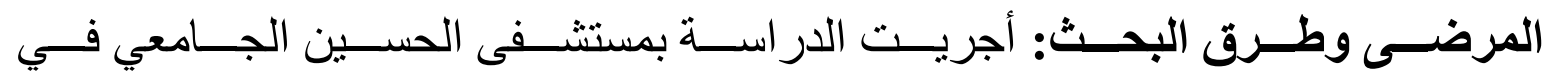

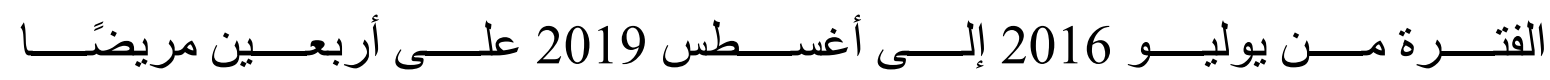

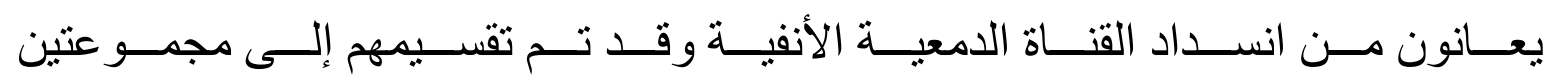

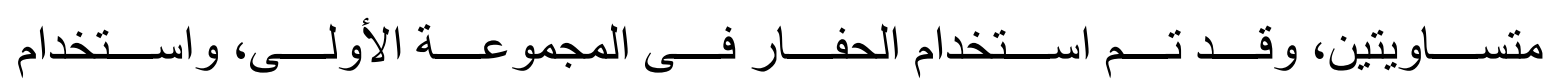

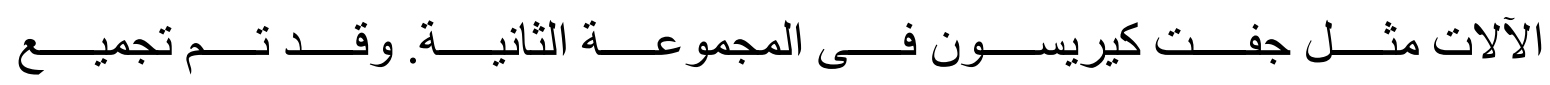

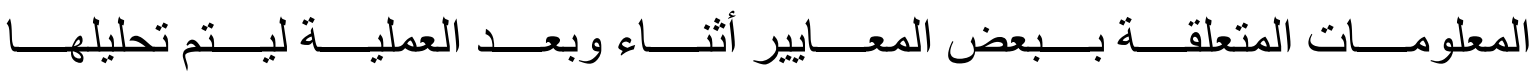
إحصائياً للار اسة.

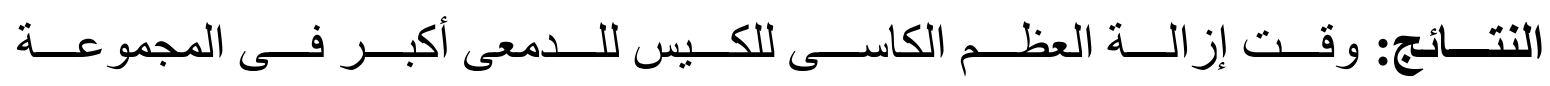

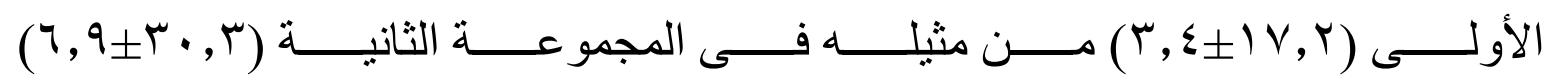




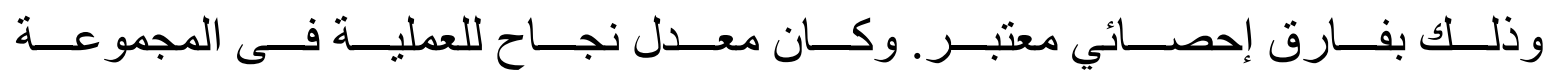

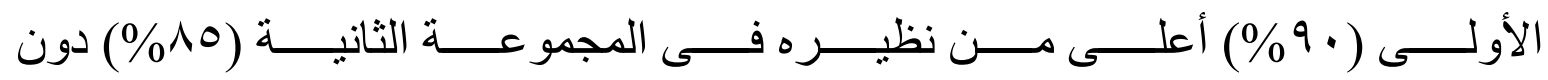

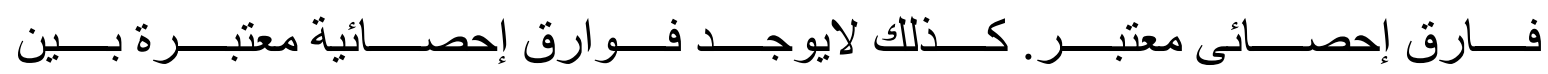

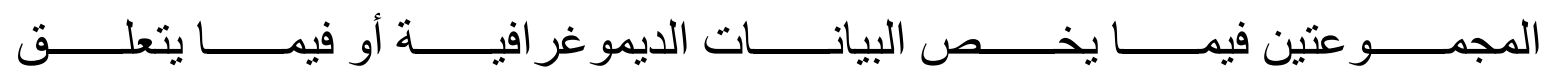
بالمضاعفات الطفيفة.

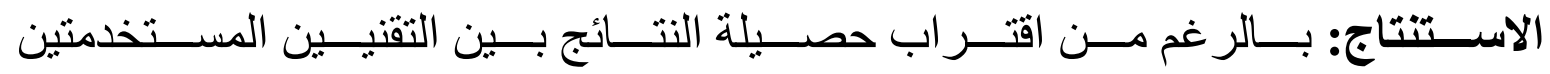

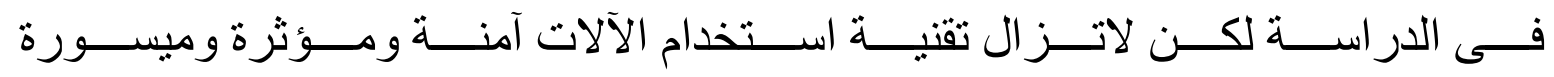
وتستهلك وفتًا أقل من التقنية المدعومة بالطاقة. 